\title{
The Relationship between Covert Narcissism and Relational Aggression in Adolescents: Mediating Effects of Internalized Shame and Anger Rumination
}

\author{
Sung Chan Ghim, Doo Hwan Choi, Ji Jun Lim, and Sung Moon Lim
}

\begin{abstract}
The purpose of this study was to test the pass model of the causal relationships among covert narcissism, internalized shame, anger rumination, and relational aggression. Also, another purpose was to verify internalized shame and anger rumination mediated between covert narcissism and relational aggression. For this study, data were collected from 653 students (336 males, 317 females) at eleven Korean high schools and were analyzed with the method of structural equation modeling. The results supported our hypothetical model. First, our findings in this study demonstrated that covert narcissism was associated with relational aggression. Second, path analysis revealed that both internalized shame and anger rumination mediated the relationship between covert narcissism and relational aggression. In addition, anger rumination mediated the relationship between internalized shame and relational aggression. Implications for future research and clinical practice are discussed.
\end{abstract}

Index Terms - Covert narcissism, internalized shame, anger rumination, relational aggression.

\section{INTRODUCTION}

School violence and bullying issues are an important problem facing adolescents for many years in South Korea. In the last few decades, researchers in the field of aggression and bullying have begun to examine covert and indirect forms of aggression such as relational, social or indirect aggression [1]-[4]. For these types of aggression as opposed to physical and verbal aggression, we use here the term "relational aggression" to be consistent and avoid confusion.

As defined by Crick and her colleagues, relational aggression refers to both covert and overt behaviors intended to harm others through the damage and manipulation of relationships [1], [5], [6]. Examples of relationally aggressive behaviors include: exclusion from a group, spreading mean rumors, and threatening to end friendships (e.g., "I won't to be your friend unless you do what I say"; [1]).

These constructs are similar to one another by definition of social or indirect aggression. Examples of social aggressive behaviors include: in addition to manipulative behaviors used for relational aggression, a broader spectrum of behaviors that damage peers' self-esteem, social status, and reputations (e.g., facial expressions of disdain, gossiping). Examples of

Manuscript received October 25, 2013; revised January 22, 2014.

S. C. Ghim and S. M. Lim are with Chungbuk National University, Korea (e-mail: cahn72@daum.net, sungmoon@chungbuk.ac.kr).

D. H. Choi is with Cheongmyeong Institute for Students, Korea (e-mail: kingstar77@cbe.go.kr).

J. J. Lim is with Bucheon St. Mary's Hospital, Korea (e-mail: lj2realstyle@naver.com). indirect aggressive behaviors include: such as ignoring and social exclusion, which are similar to relational and social aggression, but it also includes behaviors that are not directly related to manipulation of relationships (e.g., criticizing one's hair or clothing). But relational aggression includes those specific behaviors that reflect intent to harm others through the damage and manipulation of relationships [6].

Several studies in this area have also demonstrated that relational aggression is one of the favorite forms of violence frequently experienced and instigated by high school students (e.g., [7]). Exposure to bullying, physical violence and relational aggression may result in an array of negative outcomes, such as physical health, psychosocial health and lower sense of well-being [2]-[4]. A substantial body of research has reported consistent, negative outcomes for both the perpetrators and the victims of relational aggression, including social alienation, rumor spreading and the manipulation of a relationship to cause psychological harm to an individual (e.g., [6]).

In addition to the study on the outcomes and correlates of relational aggression, many efforts have been made to identify the antecedents of relational aggression, and one of the major areas of research has been narcissism. There has been an increase in recent years in the number of psychological studies that have looked at the relationships between narcissism and aggression.

In a comprehensive literature review, several theorists proposed that hostile aggression most commonly occurs when inflated views of self and unstable beliefs in personal superiority are threatened (e.g., [8]). These conceptions of excessive self-love are relevant to narcissism. And the term of narcissism comes from the mythical Greek character Narcissus about a handsome young man who falls in love with his own reflection in the water [9]. Most current psychological research focuses on "normal narcissism" operationalized as a trait on which people in the general population [10]. Narcissism has been described as a "mixed-blessing" because it comprises adaptive and maladaptive features. On the one hand, narcissists can be confident, perform well under pressure, and implement self-regulatory tactics that preserve self-esteem [11], [12]. On the other hand, narcissists tend to be impulsive, fail to learn from their mistakes, and-perhaps most concerning-are prone to many forms of aggression including verbal, physical, and violence [8], [9], [11], [12]. Some of these studies have focused on the narcissistic aggression.

Preliminary evidence suggests that aggression tends to relate positively to narcissism [13]-[16]. Furthermore, Bushman and his colleagues found that, with older adolescent samples, a combination of high narcissism and high 
self-esteem may be associated with relatively high levels of aggression [17]. The highest levels of aggression were found among people who have emotional and motivational investment in extremely favorable, grandiose self-images. It is also noteworthy that narcissism led to increased aggression independently of ego threat, as indicated by a main effect [8], [9], [18].

Recently, several clinical psychologists have suggested that narcissism can be divided into overt or observable and covert or hidden subtypes (e.g., [19]-[22]). Both types of narcissists present as extraordinarily self-absorbed and arrogant, but in other respects, overt and covert narcissists are distinguishable from one another. Covert narcissists are emotionally depleted, lack energy, and are relatively unhappy (e.g., [19], [23]).

This distinction has been theoretically accepted and empirically supported [22], [24]. Overt narcissists tend to experience a grandiose sense of self and demand the attention of others, even though they are relatively oblivious to the needs of others. On the other hand, covert narcissists are hypersensitive to the negative evaluation made by others, and are generally dissatisfied [23].

In the majority of narcissism studies (e.g., [25]) several researchers have been focused on overt narcissism and aggression. But some studies showed that covert narcissism is associated with increased relational aggression in adolescents [26]-[28]. Also, in a study focused on narcissistic aggression, Baeck and Hyun [29] found that, compared with overt narcissists, covert narcissists have a greater tendency to suppress their anger and hostility.

There are relatively few studies on covert narcissism compared to overt narcissism in interpersonal violence literature. In addition, those studies in which the focus has been on the association between covert narcissism and aggression have a weak positive relationship [30]. On the basis of previous studies, we hypothesized that the association between covert narcissism and relational aggression would be mediated by internalized shame based on the emotion dysregulation model [31]. In this model, emotion disruption and dysregulation may be reflected in 1) heightened intensity of emotions; 2) poor understanding of emotions; 3 ) negative reactivity to one's emotional state (e.g., fear of emotion); and 4) maladaptive emotional management responses.

One of the difficulties of studying shame is a lack of clarity of definition. Shame is described as an emotion, a disposition, and an attitude [32]. Shame is "the product of a complex set of cognitive activities: the evaluation of an individual's actions in regard to her standards, rules, and goals, and her global evaluation of the self" [33]. When feeling shame, the entire self is painfully scrutinized and negatively evaluated. The phenomenological experience of the person feeling shame is that of a wish to hide, disappear, or die. Shame involves a sense of shrinking, of being small, and of being worthless and powerless [34]-[36]. Although shame often involves a sense of exposure, it is often reported when not in the presence of others [37]. The shamed individual seeks to hide, escape, or blame others for the situation. Thus, shame often motivates an avoidance response, which is likely to limit interpersonal contact.

With regard to trait shame in particular, several researchers have published studies that related internalized shame and numerous variables: addiction [38], attachment [38], narcissistic personality [39]-[41], and violence and rage [42].

Harder and Lewis [43] reported a negative correlation between a measure of narcissism and one of shame, treating it as evidence that there are two patterns of relationship between narcissism and shame. But Some theorists have suggested that one type of narcissism, characterized by an aggressive, grandiose, phallic style, would not be accompanied by shame, and in fact might be characterized by denial of shame; whereas another type of narcissism, characterized by intensely idealized self and object representations, would be more likely to be accompanied by consciously experienced shame [40], [44], [45]. Furthermore, Hibbard [46] found that narcissism seemed to divide into two different styles, a phallic, grandiose style and a narcissistically vulnerable style. Shame primarily accounted for the differences in these styles, correlating negatively with the grandiose style, positively with the more vulnerable style.

Shame has received relatively little attention in interpersonal violence literature. It may, however, be an important predictor of aggression, particularly because of its relationship with anger. Shame is a powerful negative emotion believed to result from a heightened awareness (whether real or imagined) of negative evaluation from others [36].

When shamed, individuals experience an overall negative sense of self-worth and powerlessness, especially in relation to the source of the negative evaluation [34]-[36]. Shame often results in feelings of humiliation and the desire to shrink or hide away. Lewis [36], however, hypothesized that shamed individuals may also become hostile, especially toward the source of the threat, perhaps in an attempt to regain feelings of self-worth and control. Empirical research supports this hypothesized relationship between shame and anger. For example, Champman and his colleagues [47] showed that shame is associated with increased anger. Similarly, in a case study, Bradshaw [48] found that shame was significantly correlated with levels of both abusiveness and anger.

Based on the literature, we hypothesized that the association between internalized shame and relational aggression would be mediated by anger rumination based on the cognitive emotion regulation strategies [49]. The terms 'cognitive coping' and 'cognitive emotion regulation' are used as interchangeable terms. Generally speaking, both concepts can be understood as the cognitive way of managing the intake of emotionally arousing information [50]. The regulation of emotions through cognitions is inextricably associated with human life. Cognitions or cognitive processes may help us to manage or regulate emotions or feelings, and to keep control over our emotions and/or not getting overwhelmed by them, for example, during or after the experience of threatening or stressful events.

Rumination or focus on thought refers to thinking about the feelings and thoughts associated with the negative event [51]-[55]. It has been shown that a ruminative coping style tends to be associated with higher levels of violence [56], [57] and relational aggression [58].

On the basis of previous studies, we hypothesized that the association between covert narcissism and relational 
aggression would be mediated by internalized shame and the anger rumination.

The aim in the present study is to test the pass model of causal relationships among the variables of covert narcissism, internalized shame, anger rumination, and relational aggression. Also another aim in this study is to examine the role of internalized shame and anger rumination as mediators in the relationship between covert narcissism and relational aggression. Our hypotheses are as follows; 1) covert narcissism, internalized shame, anger rumination, and relational aggression will be positively related, and 2) there will be a sequence in which internalized shame led to anger rumination which, in turn, led to relational aggression (i.e., internalized shame $\rightarrow$ anger rumination $\rightarrow$ relational aggression). The proposed model is presented in Fig. 1.

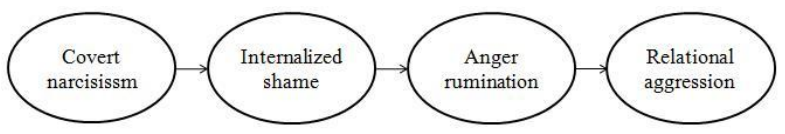

Fig. 1. Proposed model.

\section{METHOD}

\section{A. Participants and Procedure}

Data were collected from 737 students at eleven high schools located in South Korea. After excluding participants who did not respond to more than $10 \%$ of the total questions, data from 653 subjects were analyzed. Of the participants, 336 were boys $(51.5 \%)$ and 317 were girls $(48.5 \%) ; 325$ $(49.8 \%)$ sixteen years; 202 (30.9\%) seventeen years; and 126 $(19.3 \%)$ eighteen years. The characteristics of the participants are presented in Table I.

TABLE I: CHARACTERISTICS OF THE PARTICIPANTS $(N=653)$

\begin{tabular}{|c|c|c|c|c|c|}
\hline Age & & 16yesrs & 17years & 18years & Total (\%) \\
\hline \multirow{2}{*}{ Gender } & Male & 209 & 101 & 26 & $336(51.5)$ \\
\hline & Female & 116 & 101 & 100 & $317(48.5)$ \\
\hline $\operatorname{Total}(\%)$ & & $325(49.8)$ & $202(30.9)$ & $126(19.3)$ & $653(100.0)$ \\
\hline
\end{tabular}

\section{B. Measures}

Covert Narcissism. Covert narcissism was measured using the Covert Narcissism Scale (CNS) [59], which is a 5-point scale of 45 items that was developed for nonclinical populations. The CNS is composed of covert narcissism factors (hypersensitive/vulnerable, unstable goal-seeking, and timid/lacking confidence subscales) and common factors of narcissism (grandiose/exhibitionistic and exploitative subscales). The internal reliability for the measure was acceptable, with a Cronbach's alpha of .90. Internal consistency for the CNS scales in this study was satisfactory: total overt $=0.92 ;$ reactive overt $=0.86 ;$ proactive overt $=$ 0.87 ; total relational $=0.88$; reactive relational $=0.80$; proactive relational $=0.76$.

Internalized Shame. Internalized shame was measured using the Korean version of the Internalized Shame Scale (ISS) [60]. The ISS consists of 30 Likert-scaled items designed to measure enduring, chronic shame that has become an internalized part of one's identity. The shame score is based entirely on responses to the 24 negatively worded "shame" items. The remaining six items are positively worded "self-esteem" items, which are included to reduce response set. The internal reliability for the measure was acceptable, with a Cronbach's alpha of .89.

Anger Rumination. Anger rumination was measured using the Korean version of the Anger Rumination Scale (ARS) [53]. The K-ARS measures the tendency to think about current anger provoking situations and recall angry episodes from the past. It comprises 16 items, which load on three factors. Angry memories (I ponder about the injustices that have been done to me), thoughts of revenge (I have long living fantasies of revenge after the conflict is over), and understanding causes (I think about the reasons people treat me badly). The items are rated on a four point Likert scale ranging from $1=$ almost never to $4=$ almost always. Possible scores on the angry afterthoughts range from 6 to 42 with higher scores indicating more angry afterthoughts. Overall the scale has been demonstrated to have adequate reliability and validity with a Cronbach's alpha of .93 [53]. The internal reliability for the measure was acceptable, with a Cronbach's alpha of .93.

Relational Aggression. Peer conflict was measured using the Korean version of the Peer Conflict Scale (PCS) [61]. The PCS was developed based on items from existing rating scales assessing reactive, proactive, overt, and relational aggression. The PCS was created to overcome certain limitations of past aggression measures, including narrowly worded items (e.g., proactive items assessing only aggression for gain but not for dominance or sadistic reasons) and items not directly assessing harm to a victim. All items were reworded to ensure that there was direct correspondence between overt and relational items, such that for each reactive overt item there was an analogous reactive relational item, and for each proactive overt item there was an analogous proactive relational item. This process led to the creation of a self-report measure including ten items in each of four aggression categories: proactive overt ("I start fights to get what I want"), proactive relational ("I gossip about others to become popular"), reactive overt ("When someone hurts me, I end up getting into a fight"), and reactive relational ("If others make me mad, I tell their secrets"). Items are rated on a four point scale $(0=$ "not at all true", $1=$ "somewhat true", $2=$ "very true", and $3=$ "definitely true") and scores are calculated by summing the ten items separately for the four subscales (range $=0$-30 for each subscale). Scores for overall overt and relational aggression can also be calculated by summing the 20 items that comprise their respective subscales (range $=0-60$ ). Internal consistency for the PCS scales in this study was satisfactory: total overt $=0.92$; reactive overt $=0.86$; proactive overt $=0.87$; total relational $=$ 0.88 ; reactive relational $=0.80$; proactive relational $=0.76$.

\section{Analyses}

Using SPSS, we conducted correlation analysis in order to investigate the relationships among covert narcissism, internalized shame, anger rumination, and relational aggression. A path analysis was conducted using AMOS to test the goodness-of-fit of pass model of causal relationship among these variables.

CFI (Comparative Fit index), TLI (Tucker-Lewis Index), NFI (Normed Fit Index), and RMSEA (Root Mean Square Error of Approximation) were used for indices of goodness of fit. And chi-square test which is sensitive to sample size was considered in the evaluating the goodness of fit of the model. 
In general, RMSEA is interpreted as "good" if it is below .05, as "reasonable" if below .08, and as "not good" if above .10 [62]. The model is considered to be acceptable when the index score of TLI, CFI, NFI is above .90 .

\section{RESULTS}

\section{A. Descriptive Statistics and Correlations}

Table II contains the Pearson correlation matrix for all variables in this study. All correlations are statistically significant. Covert narcissism was positively related to internalized shame $(r=.714, p<.01)$, anger rumination $(r$ $=.546, p<.01)$, and relational aggression $(r=.257, p<.01)$. Internalized shame was positively related to anger rumination $(r=.499, p<.01)$, and relational aggression $(r=.196, p<.01)$. Anger rumination was positively related to relational aggression $(r=.385, p<.01)$.

\begin{tabular}{|c|c|c|c|c|}
\hline \multicolumn{5}{|c|}{ TABLE II: CORRELATIONS AMONG VARIABLES } \\
\hline Variable & 1 & 2 & 3 & 4 \\
\hline 1. Covert narcissism & 1 & & & \\
\hline 2. Internalized shame & $.714^{* *}$ & 1 & & \\
\hline 3. Anger rumination & $.546^{* *}$ & $.499 * *$ & 1 & \\
\hline 4. Relational aggression & $.257 * *$ & $.196^{* *}$ & $.385^{* *}$ & 1 \\
\hline M & 75.70 & 35.75 & 30.99 & 6.74 \\
\hline SD & 15.33 & 16.67 & 10.18 & 7.75 \\
\hline
\end{tabular}

\section{B. Path Analysis from Covert Narcissism to Relational} Aggression by Internalized Shame and Anger Rumination

The measurement model was implemented before conducting test of the structural model to examine if the latent variables were well estimated by manifest variables. The path coefficient of the measurement model is shown in Fig. 2.

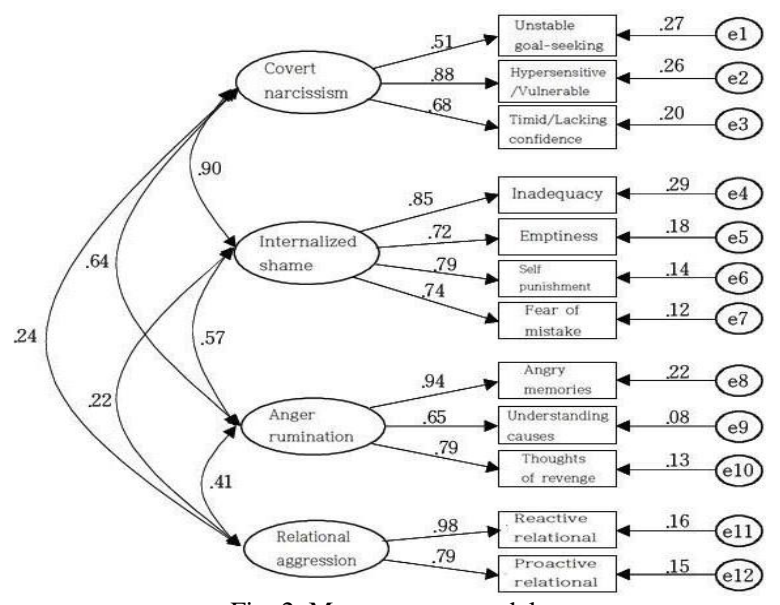

Fig. 2. Measurement model.

Fig. 2 shows that every path was statistically significant ( $p$ $<.001)$.

The hypothesized model provided a good fit to the data. The $\chi^{2}$ value was not rejected ( $\left.p>.001\right)$. Also, CFI (.945), TLI (.925), and NFI (.936) were all greater than .90 and the RMSEA (.092) was at an appropriate level. Therefore, it can be concluded that the model fit of the measurement model is acceptable and the analysis can be proceeded to the structural model. These findings are illustrated in Table III.

Given that the appropriate measurement model was established, the test of structural model was performed succeedingly. Through analysis of structural model, the hypothesized causal relations based on underlying theory can be investigated.

The goodness-of-fit of the structural model was reasonable; $\chi^{2}(d f=51, N=653)=339.627, p<.001 ; \mathrm{CFI}=.941 ; \mathrm{TLI}$ $=.923 ; \mathrm{NFI}=.931 ; \mathrm{RMSEA}=.093$. These findings are illustrated in Table III.

TABLE III: THE GOODNESS-OF-FIT OF MEASUREMENT MODEL AND STRUCTURAL MODEL

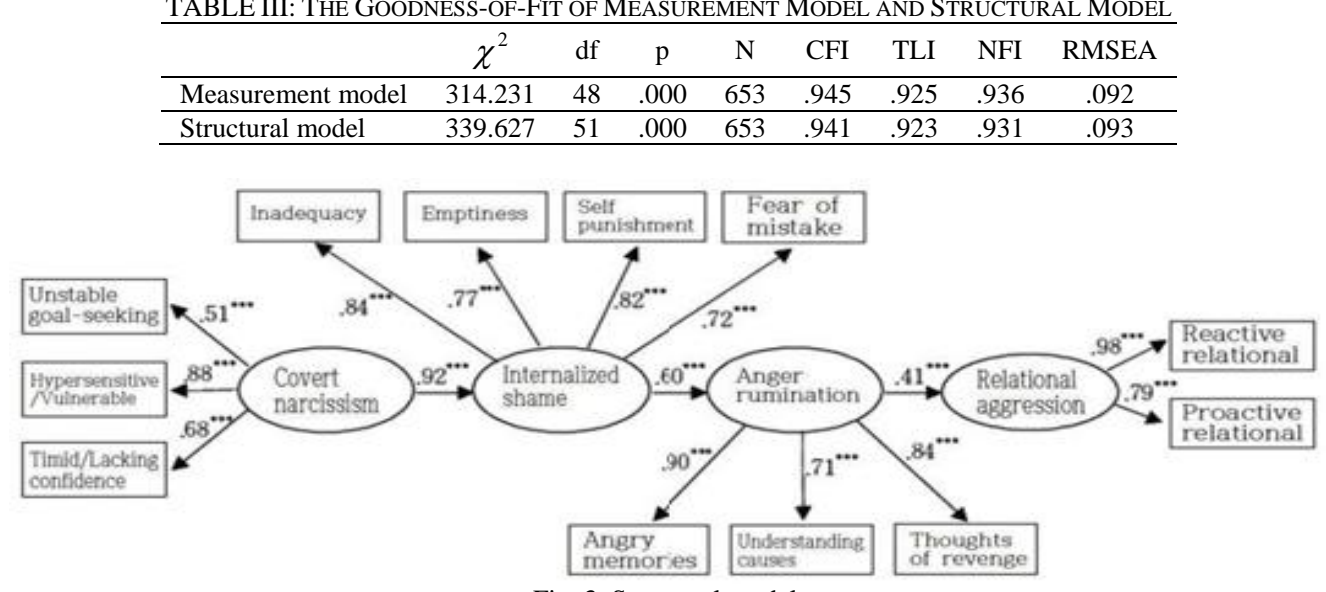

Fig. 3. Structural model.

Structural equation modeling analysis was conducted to test for the hypothesizing structural model presented in Fig. 3 .

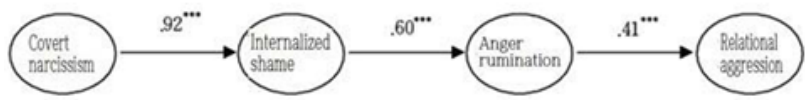

Fig. 4. Research model.

Fig. 3 shows that every path was statistically significant ( $p$ $<.001)$.

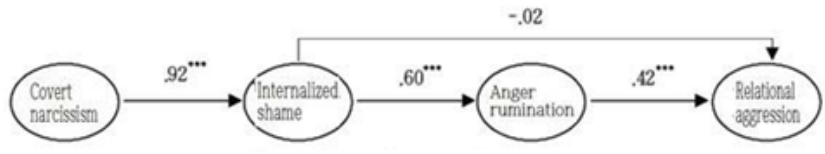

Fig. 6. Competing model 2

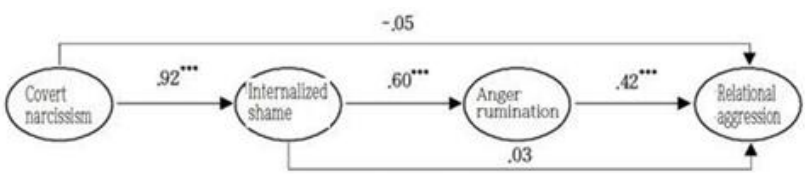

Fig. 7. Competing model 3. 
Based on our hypotheses in the present study, our research model (Fig. 4) was compared with the competing models (Fig. 5-Fig. 7).

A summary of goodness-of-fit indices for each model is presented in Table IV. As can be seen in the table, and the fit of the research model was better than that of the competing models. Specifically, the ratio of the minimum discrepancy divided by its degrees of freedom $\left(\chi^{2} / d f\right)$ suggested that the hypothesized model fits the data better than the two competing models. Although a $\chi^{2} / d f$ of less than 2 is regarded as an ideal value, Bollen [63] warned that $\chi^{2} / d f$ estimates do not correct the excessive power problem, thereby warranting caution in applying this rule of thumb. The observed value of RMSEA was .093, and its $90 \%$ confidence interval includes .05, which demonstrates that the hypothesized model is a good fit with the data. The other fit indices (CFI $=.941, \mathrm{GFI}=.923$, and NFI $=.931)$ also indicated a very good fit with the hypothesized model. To conclude, the goodness-of-fit indices supported the adequacy of the hypothesized theoretical model.

TABLE IV: THE GOODNESS-OF-FIT OF RESEARCH MODEL AND COMPETING MODEL

\begin{tabular}{|c|c|c|c|c|c|c|c|c|}
\hline & $\chi^{2}$ & $d f$ & $p$ & $N$ & $C F I$ & $T L I$ & $N F I$ & RMSEA \\
\hline Research model & 339.627 & 51 & .000 & 653 & .941 & .923 & .931 & .093 \\
\hline Competing model 1 & 339.314 & 50 & .000 & 653 & .941 & .921 & .931 & .094 \\
\hline Competing model 2 & 339.406 & 50 & .000 & 653 & .940 & .921 & .931 & .094 \\
\hline Competing model 3 & 339.265 & 49 & .000 & 653 & .940 & .920 & .931 & .095 \\
\hline
\end{tabular}

TABLE V: PATH COEFFICIENTS AND $T$-VALUES OF THE MODEL

\begin{tabular}{l|l|l|l|l|l|l}
\hline Valuable & $\rightarrow$ & $b$ & $\beta$ & $S E$ & $t$ \\
\hline Covert narcissism & $\rightarrow$ & Internalized shame & 1.640 & .927 & .127 & 12.914 \\
\hline Internalized shame & $\rightarrow$ & Anger rumination & .270 & .606 & .001 & .019 \\
\hline Anger rumination & $\rightarrow$ & Relational aggression & .654 & .412 & .057 & 14.359 \\
\hline \multicolumn{2}{c|}{ Squared Multiple Correlations } & .001 \\
\hline
\end{tabular}

\begin{tabular}{|l|l|l|}
\hline \multicolumn{2}{|c|}{ Squared Multiple Correlations } \\
\hline Internalized shame & & .860 \\
\cline { 1 - 1 } & & .367 \\
\hline Anger rumination & & .170 \\
\hline
\end{tabular}

The hypothesized causal paths between independent and dependent variables were estimated as path coefficients. Table $\mathrm{V}$ presents the statistically significant paths with standard coefficients and level of significance. Among 8 exogenous variables, influence of covert narcissism on internalized shame is the greatest $($ std. coefficient $=.927 * * *)$, and that of anger rumination on relational aggression is least powerful $(.412 * * *)$. The three causal paths in the research model were found to be statistically significant $(p<.001)$.

As predicted, covert narcissism was not directly linked to relational aggression. Rather, it was related to these variables only indirectly through internalized shame in which anger rumination were found to play a pivotal role.

\section{CONCLUSION}

The current study was conducted to explore mediators of the relationship between covert narcissism and relational aggression of adolescents. Consistent with our hypotheses, we found that there is a sequence in which internalized shame lead to anger rumination which, in turn, lead to relational aggression (i.e., internalized shame $\rightarrow$ anger rumination $\rightarrow$ relational aggression).

In terms of counseling practice, the results of this study will be useful for understanding adolescents who commit relational aggression, by understanding better how their emotional processes unfold. In addition, the implications of this study will help counselors to plan treatment interventions in order to decrease relational aggressive behaviors of covert narcissistic adolescents.

\section{REFERENCES}

[1] N. R. Crick and J. K. Grotpeter, "Relational aggression, gender, and social-psychological adjustment," Child Development, vol. 66, no. 3, pp. 710-722, 1995 .
[2] S. L. Hazaleus and J. L. Deffenbacher, "Relaxation and cognitive treatment of anger," Journal of Consulting and Clinical Psychology, vol. 54, pp. 222-226, 1986

[3] L. Owens, P. Slee, and R. Shute, "'It hurts a hell of a lot...'-The effects of indirect aggression on teenage girls," School Psychology International, vol. 21, no. 4, pp. 359-376, 2000.

[4] H. S. Pan, P. H. Neidig, and K. H. O'Leary, "Predicting mild and severe husband-to-wife physical aggression," Journal of Consulting and Clinical Psychology, vol. 62, pp. 975-981, 1994.

[5] N. R. Crick, M. A. Bigbee, and C. Howes, "Gender differences in children's aggression: How do I hurt thee? Let me count the ways," Child Development, vol. 67, pp. 1003-1014. 1996.

[6] N. R. Crick, J. F. Casas, and H. C. Ku, "Relational and physical forms of peer victimization in preschool," Developmental Psychology, vol. vol. 35, no. 2, pp. 376-385, 1999.

[7] R. Loeber and D. Hay, "Key issues in the development of aggression and violence from childhood to early adulthood," Annual Review of Psychology, vol. 48, pp. 371-410, 1997.

[8] R. F. Baumeister, L. Smart, and J. M. Boden, "Relation of threatened egotism to violence and aggression: The dark side of high self-esteem," Psychological Review, vol. 103, pp. 5-33, 1996.

[9] B. J. Bushman and R. F. Baumeister, "Threatened egotism, narcissism, self-esteem, and direct and displaced aggression: Does self-love or self-hate lead to violence?" Journal Personality and Social Psychology, vol. 75, pp. 219-229, 1998 .

[10] R. Raskin et al., "Narcissism, self-esteem, and defensive self-enhancement," Journal of Personality, vol. 59, pp. 19-38, 1991.

[11] American Psychiatric Association, Diagnostic and Statistical Manual of Mental Disorders, 3rd ed., Washington, DC: Author, 1980.

[12] American Psychiatric Association, Diagnostic and Statistical Manual of Mental Disorders, 4rd ed., Washington, DC: Author, 2000.

[13] R. F. Baumeister, B. J. Bushman, and W. K. Campbell, "Self-esteem, narcissism, and aggression: Does violence result from low self-esteem or from threatenede egotism?" Current Directions in Psychological Science, vol. 9, no. 1, pp. 26-29, 2000.

[14] D. K. Lapsly and M. C. Aalsma, "An empirical typology of narcissism and mental health in late adolescence," Journal of adolescence, vol. 29, no. 1, pp. 53-71, 2006.

[15] D. E. Reidy, A. Zeichner, J. D. Foster, and M. A. Martinez, "Effect of narcissistic entitlement and exploitativeness on human physical aggression," Personality and Individual Differences, vol. 44, no. 4, pp. 865-875, 2008.

[16] C. Salmivalli, "Feeling good about oneself, being bad to others? Remarks on self-esteem, hostility, and aggressive behavior," Aggression and Violent Behavior, vol. 6, no. 4, pp. 375-393, 2001. 
[17] B. J. Bushman, R. F. Baumeister, S. Thomaes, E. Ryu, S. Begeer, and S G. West, "Looking again, and harder, for a link between low self-esteem and aggression," Journal of Personality, vol. 77, no. 2, pp. 427-446, 2009.

[18] B. P. Papps and R. E. O'Carroll, "Extremes of self-esteem and narcissism and the experienced expression of anger and aggression," Aggressive Behavior, vol. 24, pp. 421-438, 1998.

[19] S. Akhtar and J. A. Thomson, "Overview: Narcissistic personality disorder," American Journal Psychiatry, vol. 139, no. 1, pp. 12-20, 1982.

[20] G. D. Atlas and M. A. Them, "Narcissism and sensitivity to criticism: A preliminary investigation," Current Psychology, vol. 27, no. 1, pp 62-76, 2008.

[21] A. M. Cooper, "Further developments in the clinical diagnosis of narcissistic personality disorder," in F. Elsa and Ronningsta, Eds. Disorders of Narcissism: Diagnostic, Clinical and Empirical Implication, London: Jason Aronson Inc., pp. 53-73, 2000.

[22] P. Wink, "Two faces of narcissism," Journal of Personality and Social Psychology, vol. 61, pp. 590-597, 1991.

[23] H. Kohut, The Restoration of the Self, New York: International Universities Press, 1977.

[24] H. M. Hendin and J. M. Cheek, “Assessing hypersensitive narcissism: A reexamination of Murray's Narcism Scale," Journal of Research Reports, vol. 79, pp. 161-162, 1997.

[25] L. M. Bogart, E. G. Benotsch, and J. D. Pavlovic, "Feeling superior but threatened: The relation of narcissism to social comparison," Basic and Applied Social Psychology, vol. 26, no. 1, pp. 35-44, 2004.

[26] C. F. David and J. A. Kristner, "Do positive self-perceptions have a "dark side"? Examination of the link between perceptual bias and aggression," Journal of Abnormal Child Psychology, vol. 28, pp. 327-337, 2000.

[27] S. E. Hymel, K. H. Rubin, L. Rowden, and L. Kemare, "Children's peer relationship: Longitudinal prediction of internalizing and externalizing prediction from middle to late childhood," Child Development, vol. 61, pp. 2004-2021, 1990.

[28] C. J. Patterson, J. B. Kupersmidt, and P. C. Griesler, "Children's perceptions of self and of relationship with others as a function of sociometric status," Child Development, vol. 61, pp. 1335-1349, 1990.

[29] S. H. Baeck and M. H. Hyun, "Hostility, anger experience and anger expression in overt and covert narcissists [In Korean]," The Korean Journal of Clinical Psychology, vol. 27, pp. 1001-1017, 2008.

[30] C. T. Barry, J. D. Picard, and L. L. Ansel, "The associations of adolescent invulnerability and narcissism with problem behaviors," Personalty and Individual Difference, vol. 47, pp. 577-582, 2009.

[31] D. D. Mennin, R. G. Heimberg, C. L. Turk, and D. M. Fresco, "Preliminary evidence for and emotion dysregulation model of generalized anxiety disorder," Behavior Research and Therapy, vol. 43, pp. 1281-1310, 2005.

[32] C. Schneider, Shame, Exposure, and Privacy, Exposre, Boston: Beacon Press, 1977.

[33] M. Lewis, Shame: The Exposed Self, New York: The Free Press, 1992.

[34] S. Allan, P. Gilbert, and K. Goss, "An exploration of shame measures-II," Psychopathology, Personality and Individual Difference, vol. 17, pp. 719-722, 1994.

[35] G. Kaufman, The Psychology of Shame: Theory and Treatment of Shame-based Syndromes, New Yok: Springer Publishing Company Inc., 1989.

[36] H. B. Lewis, Shame and Guilt in Neurosis, New York: International Universities Press, 1971

[37] J. P. Tangney, R. S. Miller, L. Flicker, and D. H. Barlow, “Are shame, guilt and embarrassment distinct emotions?" Journal of Personality and Social Psychology, vol. 70, pp. 1256-1269, 1996.

[38] D. R. Cook, "Shame, attachment, and addictions: Implications for family therapists," Contemporary Family Therapy, vol. 13, pp 405-419, 1971

[39] R. Gramzow and J. P. Tangney, "Proneness to shame and the narcissistic personality," Personality and Social Psychology Bulletin, vol. 18, pp. 369-376, 1992.

[40] A. P. Morrison, "Shame, the ideal self, and narcissism," Contemporary Psychoanalysis, vol. 19, pp. 295-318, 1983.

[41] M. Wilson, "Creativity and shame reduction in sex addiction treatment," Sexual Addiction \& Compulsivity, vol. 7, pp. 229-248, 2000.

[42] D. Balcom, "Shame and violence: Considerations in couples' treatment," Journal of Independent Social Work, vol. 5, pp. 3-4, 1991.

[43] D. W. Harder and S. J. Lewis, "The assessment of shame and guilt," in J. N. Butcher and C. D. Spielberger, Eds., Advances in Personality Assessment, Hillsdale, NJ, England: Laurence Erlbaum \& Associates, vol. 6 , pp. 89-114, 1987.
[44] O. F. Kernberg, Borderline Conditions and Pathological Narcissism, New York: Aronson, 1975

[45] H. Kohut, The Analysis of the Self, New York: International Universities Press, 1971.

[46] S. Hibbard, "Narcissism, shame, masochism, and object relations: An exploratory correlational study," Psychoanalytic Psychology, vol. 9, pp. 489-508, 1992.

[47] A. L. Champman, K. L. Gratz, and M. Z. Brown, "Solving the puzzle of deliberate self-harm: The experiential avoidance model," Behaviour Research and Therapy, vol. 44, pp. 371-394, 2006.

[48] J. Bradshaw, Healing the Shame that Binds You, Florida: Health Communication Incorporation, 1988.

[49] N. Garnefski, V. Kraaij, and P. Spinhoven, "Negative life events, cognitive emotion regulation and emotional problems," Personality and Individual Differences, vol. 30, pp. 1311-1327, 2001.

[50] R. A. Thompson, "Emotional regulation and emotional development," Educational Psychology Review, vol. 3, pp. 269-307, 1991.

[51] R. Langlois, M. H. Freeston, and R. Ladouceur, "Differences and similarities between obsessive intrusive thoughts and worry in a non-cinical population: Study 2," Behavior Research and Therapy, vol. 38 , pp. $175-189,2000$

[52] S. Nolen-Hoeksema, "Responses to depression and their effects on the duration of depressive episodes," Journal of Abnormal Psychology, vol. 100, no. 4, pp. 569-582, 1991.

[53] D. G. Sukhodolsky, A. Golub, and E. N. Cromwell, "Development and validation of the anger rumination scale," Personalty and Individual Difference, vo. 31, pp. 689-700, 2001.

[54] D. K. Tomsen, "The association between rumination and negative affect: A review," Congnition and Emotion, vol. 20, no. 9, pp 1216-1235, 2006.

[55] E. Watkins, "Adaptive and maladaptive rumination self-focus during emotion processing," Behaviour Research \& Therapy, vol. 42, pp. 1037-1052, 2004.

[56] M. D. Anestis, J. C. Anestis, E. A. Selby, and T. E. Joiner, "Anger rumination across forms of aggression," Personalty and Individual Difference, vol. 46, no. 2, pp. 192-196, 2009.

[57] G. V. Caprara, "Indicators of aggression: The dissipation-rumination scale," Personality and Individual Differences, vol. 7, no. 6, pp 763-769, 1986

[58] M. Peled and M. M. Moretti, "Rumination on anger and sadness in adolescence fueling of fury and deepening of despair," Journal of Clinical Child and Adolescent Psychology, vol. 36, no. 1, pp. 66-75, 2007.

[59] S. H. Kang and N. W. Jung, "A study on the development and validation of the Covert Narcissism Scale [In Korean]," The Korean Journal of Counseling and Psychotherapy, vol. 14, pp. 969-990, 2002.

[60] D. R. Cook, "Measuring shame: The internalized shame scale," Alcoholism Treatment Quarterly, vol. 4, no. 2, pp. 197-215, 1987.

[61] M. A. Marsee, E. R. Kimonis, and P. J. Frick, "Peer Conflict Scale," Rating scale, University of New Orleans, 2004.

[62] S. H. Hong, "The criteria for selecting appropriate fit indices in structural equation modeling and their rationales [In Korean]," The Korean Journal of Clinical Psychology, vol. 19, pp. 161-177, 2000.

[63] K. A. Bollen, Structural Equations with Latent Variables, New York: Wiley, 1989.

Sung Chan Ghim is a student in doctorial program on counseling psychology of department of psychology in Chungbuk National University in Korea. He received his B.S. in electronic engineering from Pusan National University in Korea.

Doo Hwan Choi received his M.A. in counseling psychology from Chungbuk National University in Korea. $\mathrm{He}$ is a counselor in Cheongmyeong Institute for Students in Korea. He has licenses of qualified counselor and clinical psychologist in Korea.

Ji Jun Lim received his M.A. in clinical psychology from Seoul National University in Korea. He is a clinical psychologist in Bucheon St. Mary's Hospital in Korea. He has a license of qualified clinical psychologist in Korea.

Sung Moon Lim received his B.S., M.A. and Ph.D. degrees in counseling and clinical psychology from Korea University in Korea. He is a licensed counseling psychologist and a professor of department of psychology in Chungbuk National University in Korea. Prof. Lim has been registered in International Biographical Center, Marquis Who`s Who, American Biographical Institute since 2011. 